Article

\title{
Controlling the Incorporation of Phosphorus Functionalities on Carbon Nanofibers: Effects on the Catalytic Performance of Fructose Dehydration
}

\author{
Sebastiano Campisi ${ }^{1, *(\mathbb{D})}$, Felipe J Sanchez Trujillo ${ }^{2}$, Davide Motta ${ }^{2}$, Thomas E. Davies ${ }^{2}$, \\ Nikolaos Dimitratos ${ }^{2}$ and Alberto Villa ${ }^{1, *}$ (10) \\ 1 Dipartimento di Chimica, Università degli Studi di Milano, Milano 20133, Italy \\ 2 Cardiff Catalysis Institute, School of Chemistry, Cardiff University, Cardiff CF10 3AT, UK; \\ SanchezF@cardiff.ac.uk (F.J.S.T.); MottaD@cardiff.ac.uk (D.M.); Daviests@cf.ac.uk (T.E.D.); \\ DimitratosN@Cardiff.ac.uk (N.D.) \\ * Correspondence: Sebastiano.campisi@unimi.it (S.C.); Alberto.villa@unimi.it (A.V.); \\ Tel.: +39-025-031-4254 (S.C.); +39-025-031-4361 (A.V.)
}

Received: 13 November 2017; Accepted: 23 January 2018; Published: 27 January 2018

\begin{abstract}
Phosphorylated carbons have been reported to be effective catalysts in dehydration reactions for biomass valorization. The amount and the nature of $\mathrm{P}$ groups are a key parameter affecting the catalytic performances of functionalized materials. Herein, we investigate the role of structural and surface properties of carbon-based materials, specifically carbon nanofibers, in determining the amount of P-functionalities. In order to incorporate P groups on carbon surfaces, various carbon nanofibers $(\mathrm{CNFs})$ with different graphitization degrees have been functionalized through treatment with a $\mathrm{H}_{3} \mathrm{PO}_{4}-\mathrm{HNO}_{3}$ mixture at $150{ }^{\circ} \mathrm{C}$. The pristine materials, as well as the functionalization protocol, were properly selected to achieve an effective functionalization without drastically altering the morphology of the samples. Surface and structural properties of the synthesized functionalized materials have been investigated by means of transmission electron microscopy (TEM), X-ray photoelectron spectroscopy (XPS), and Raman spectroscopy. The catalytic behavior of phosphorylated carbon nanofibers has been evaluated in the selective dehydration of fructose to hydroxymethylfurfural (HMF) to elucidate structure-activity relationships.
\end{abstract}

Keywords: carbon materials; nanofibers; functionalization; heteroatoms; nanotechnology; biomass valorization; heterogeneous catalysis

\section{Introduction}

The ideal material to be successfully applied to catalysis should offer high surface area, high porosity and accessibility, for limiting mass transfer, and at the same time assure chemical and mechanical stability [1]. Carbon materials comply with all the above-mentioned requirements [2,3]. Furthermore, their low cost and high versatility have made carbon-based materials the natural choice for many catalytic processes [4-6]. Physical and chemical properties of this class of materials is strongly affected by the hybridization and the structural organization at local and long-range level. According to the carbon atom arrangement in the lattice, a usual classification distinguishes between graphitic materials, characterized by uniform $\mathrm{sp}^{2}$ hybridization and a highly-ordered structure, and amorphous materials (e.g., activated carbon, charcoal), where disordered and graphitic components coexist [7]. Moreover, recent discoveries led the family of carbon materials to further expand so as to include the low-dimensional allotropes (fullerenes, carbon nanotubes, carbon nanofibers, graphene) [8-10]. The use of nanostructured carbonaceous materials in catalysis resulted in the introduction of some additional advantageous features, such as confinement [11-13], electronic effects [14-16], and unique 
surface reactivity [17-19], whose extent is strongly determined by the structural parameters (e.g., diameter, length, chirality, topological defects) [20]. The latter are not easily tunable during the synthesis; therefore, it is difficult to obtain carbon nanostructured materials with tailored properties. From this point of view, the functionalization represents an alternative tool for imparting novel properties and improving catalytic performances [21,22].

The introduction of heteroatoms ( $, ~ O, P$, and $\mathrm{S}$ ) has been reported to confer higher hydrophilicity, enhanced metal-support interactions, and additional acidic or basic sites [23-32]. Obviously, the distribution, the amount, the location, and the specific binding forms of the heteroatoms on the surface strictly depend on the nature of the carbonaceous substrate. A crucial role is played by the graphitization degree, which is an index of the order degree in carbon-based materials [3]. A low graphitization degree should imply the presence of surface impurities and defects acting as preferential sites for the anchoring of functional groups. However, the relationship between the graphitization degree and the extent and the characteristics of the functionalization process need to be further investigated, mainly relative to the effect on the catalytic performances.

In this work, we investigated the role of structural and surface properties of different carbon nanofibers in determining the amount of P-functionalities and their catalytic performance. Carbon nanofibers were selected instead of classical carbon supports, such as activated carbon, since they can be easily functionalized without undergoing morphological alterations. Several efficient routes have been proposed to incorporate phosphorus on carbon materials [33]. In any case, when mild functionalization conditions are used, $\mathrm{P}$ groups are essentially attached on carbon surface by the formation of $\mathrm{C}-\mathrm{O}-\mathrm{P}$ bonds. From this point of view, using a $\mathrm{HNO}_{3}-\mathrm{H}_{3} \mathrm{PO}_{4}$ mixture represents a suitable strategy to promote the phosphorylation in mild conditions without affecting the original morphology of the samples. Indeed, the co-presence of $\mathrm{HNO}_{3}$ results in the introduction of O-functionalities on the surface, acting as preferential anchoring sites for phosphate groups [31]. As known from the literature, P-containing materials are effective catalysts in the selective dehydration of fructose to 5-hydroxymethylfurfural (HMF) in water [34-38]. Indeed, grafting P groups on the surface allowed to tune the surface acidity and resulted in more selective catalysts compared to other solid acid catalysts [37]. Therefore, the catalytic performances of P-functionalized carbon nanofibers were evaluated in this reaction, whose relevance in the field of biomass valorization is well-established.

\section{Results}

\subsection{Catalytic Fructose Dehydration}

Commercial carbon nanofibers (CNFs) from Applied Science (Cedarville, OH, US) (average diameter of $100 \pm 30 \mathrm{~nm}$ and a specific surface area of $40-45 \mathrm{~m}^{2} / \mathrm{g}$ ), thermally processed at different severity degrees [39], were selected as carbonaceous substrates. In particular vapor-grown carbon nanofibers treated at $700{ }^{\circ} \mathrm{C}$ (Pyrolytically Striped Carbon Nanofibers, PS-CNFs), $1500{ }^{\circ} \mathrm{C}$ (Low-temperature Heat Treated Carbon Nanofibers, LHT-CNFs), and $3000^{\circ} \mathrm{C}$ (High-temperature Heat Treated Carbon Nanofibers, HHT-CNFs) were used as pristine materials to study the influence of $\mathrm{CNF}$ structural properties on the incorporation of $\mathrm{P}$ groups. To introduce $\mathrm{P}$ - functionalities, carbon materials were treated with a $\mathrm{H}_{3} \mathrm{PO}_{4}-\mathrm{HNO}_{3}$ mixture at $150{ }^{\circ} \mathrm{C}$ following a modified procedure from [31]. The functionalized carbon materials, labelled as P-PS-CNFs, P-LHT-CNFs, and P-HHT-CNFs, were tested in the fructose dehydration reaction, in a batch reactor at $120{ }^{\circ} \mathrm{C}$ under diffusional control (Scheme 1). Reaction conditions were selected according to previous tests performed with phosphorylated ordered mesoporous carbon [37], in order to perform a proper comparison.

The catalytic activities of the samples are compared in Figure 1, reporting the fructose conversion as a function of the reaction time. For comparison, pristine materials (PS-CNFs, LHT-CNFs, and HHT-CNFs) were also tested with negligible activity (fructose (FRU) conversion $<2 \%$ in all cases). Among the studied materials, P-HHT CNFs exhibited the best performances in terms of activity, reaching the $45 \%$ of conversion after $3 \mathrm{~h}$ and almost completely converting fructose after $12 \mathrm{~h}(94 \%)$. 
The remaining samples, P-PS and P-LHT, showed a lower conversion (17\% and 20\%, respectively.) Moreover, these two catalysts showed deactivation after $3 \mathrm{~h}$ of reaction.

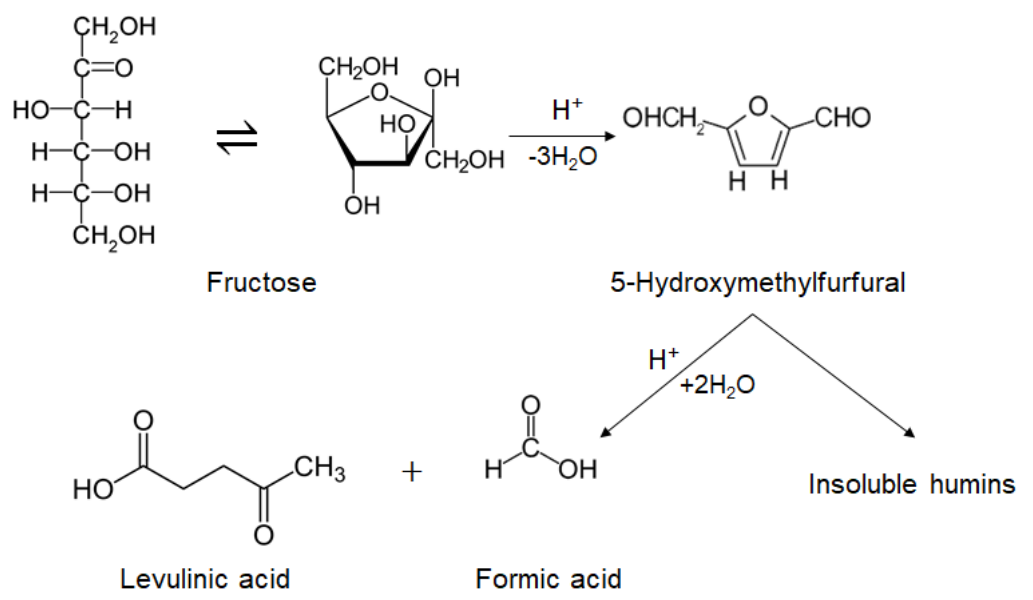

Scheme 1. Reaction scheme for fructose dehydration.

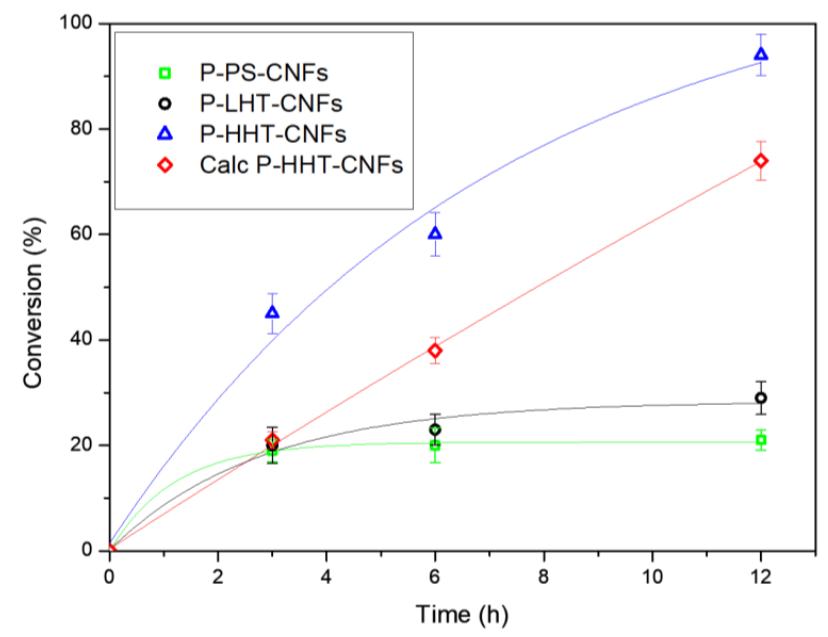

Figure 1. Conversion profiles as a function of the reaction time; (reaction conditions: fructose $5 \mathrm{wt} \%$ in water, fructose/catalyst 2:1 $\left.w / w, T=120{ }^{\circ} \mathrm{C}, p\left(\mathrm{~N}_{2}\right)=3 \mathrm{~atm}\right)$.

Concerning the selectivity to HMF (Figure 1b), the desired product from fructose dehydration, entries in Table 1 compare the performances of all the samples at increasing reaction times $(3,6$, and $12 \mathrm{~h}$ ). P-PS and P-LHT CNFs showed a very similar behavior also in terms of selectivity $\left(S_{\mathrm{HMF}}\right.$ : $45 \%$ and $49 \%$, respectively, after $12 \mathrm{~h}$ ). Despite the high activity, a low selectivity to HMF was obtained for P-HHT ( $46 \%$ after $12 \mathrm{~h}$ ), probably due to the consecutive transformation of HMF to side-products. It is known that the presence of secondary reactions, such as the formation of formic and levulinic acids or humins, is promoted by the strong acidity typical of homogenous acid catalysts [36,40-43]. When $0.1 \mathrm{M}$ phosphoric acid solution $(\mathrm{pH} \approx 2)$ is used as a homogeneous catalyst, fructose is almost completely converted after three hours (conv. $88 \%$ ), but the selectivity to HMF is quite low (52\%) and comparable to the values obtained with phosphorylated carbon nanofibers.

We ascribed, therefore, the decrease in the selectivity to HMF for P- CNFs catalysts to the possible partial leaching of phosphate groups. Indeed, filtering off the solid catalyst at the reaction temperature the reaction proceeded slowly and the selectivity to HMF decreased from $40-50 \%$ to $30 \%$. To suppress the release of phosphate group into the solution, P-HHT CNFs, showing the best catalytic performances, were calcined at $400{ }^{\circ} \mathrm{C}$ in static air. 
Table 1. Catalytic performances of all the functionalized samples in the fructose dehydration reaction after 3,6 , and $12 \mathrm{~h}$ of reaction.

\begin{tabular}{|c|c|c|c|c|c|}
\hline \multirow{2}{*}{ Catalyst } & \multirow{2}{*}{$\begin{array}{c}\text { Time of } \\
\text { Reaction (h) }\end{array}$} & \multirow{2}{*}{$\begin{array}{c}\text { Conversion } \\
(\%)\end{array}$} & \multicolumn{3}{|c|}{ Selectivity } \\
\hline & & & HMF & Levulinic Acid & Formic Acid \\
\hline \multirow{3}{*}{ P-PS-CNFs } & 3 & 17 & 54 & 2 & 7 \\
\hline & 6 & 18 & 50 & 5 & 9 \\
\hline & 12 & 19 & 48 & 7 & 11 \\
\hline \multirow{3}{*}{ P-LHT-CNFs } & 3 & 20 & 53 & 1 & 9 \\
\hline & 6 & 23 & 45 & 1 & 5 \\
\hline & 12 & 29 & 49 & 2 & 3 \\
\hline \multirow{3}{*}{ P-HHT-CNFs } & 3 & 45 & 50 & 2 & 2 \\
\hline & 6 & 60 & 49 & 6 & 4 \\
\hline & 12 & 94 & 46 & 10 & 7 \\
\hline \multirow{3}{*}{$\begin{array}{c}\text { Calc } \\
\text { P-HHT-CNFs }\end{array}$} & 3 & 21 & 87 & 2 & 2 \\
\hline & 6 & 38 & 86 & 3 & 5 \\
\hline & 12 & 74 & 81 & 6 & 8 \\
\hline $\mathrm{H}_{3} \mathrm{PO}_{4} 0.1 \mathrm{M}$ & 3 & 88 & 52 & 7 & 8 \\
\hline
\end{tabular}

Indeed, a high-temperature thermal treatment of phosphorylated carbon materials results in the formation of more stable C-P bonds less prone to leaching compared to C-O-P bonds [44]. Calcined P-HHT CNFs were then tested in the fructose dehydration reaction. The calcined sample showed a lower activity compared to the uncalcined one (21 and $45 \%$, respectively, after $3 \mathrm{~h}$ ) but with the conversion which linearly increased up to $74 \%$ after $12 \mathrm{~h}$. However, a higher selectivity to $\mathrm{HMF}$ was obtained in this case, confirming our previous hypothesis $\left(S_{\mathrm{HMF}} 81 \%\right.$ at $75 \%$ of fructose conversion). This result demonstrates the feasibility of these materials as promising catalysts for selective dehydration processes. Indeed this result is better for example than the best results obtained using phosphorylated mesoporous carbon under the same reaction conditions $\left(S_{\mathrm{HMF}} 53 \%\right.$ at $78 \%$ of conversion) [37].

A thorough characterization of the surface and structural properties of the functionalized materials was performed to provide insight into the different trends observed in terms of activity and selectivity.

\subsection{Characterization of P-Functionalized Carbon Nanofibers (CNFs)}

A combination of complementary imaging techniques, namely field-emission gun scanning electron microscopy (FEG-SEM), energy dispersive X-ray diffraction (EDX), and high-resolution transmission electron microscopy (HRTEM), was used to assess the composition and the effect of the functionalization on the microstructure of treated materials.

HRTEM analysis (Figure 2) provided evidence that the overall structure of the CNFs has not been significantly altered after the functionalization [39]. Further examination of the surface area by Brunauer-Emmett-Teller (BET) single-point measurements confirmed that no significant changes in the surface area and porosity occurred after acid treatment (Table 2).

Table 2. Surface area analysis.

\begin{tabular}{cc}
\hline Sample & Specific Surface Area $\left(\mathbf{m}^{\mathbf{2}} \mathbf{g}^{-\mathbf{1}}\right)$ \\
\hline PS-CNFs & $43 \pm 2.3$ \\
P-PS-CNFs & $45 \pm 1.8$ \\
LHT-CNFs & $38 \pm 3.3$ \\
P-LHT-CNFs & $39 \pm 4.2$ \\
HHT-CNFs & $37 \pm 0.9$ \\
P-HHT-CNFs & $36 \pm 2.1$ \\
\hline
\end{tabular}




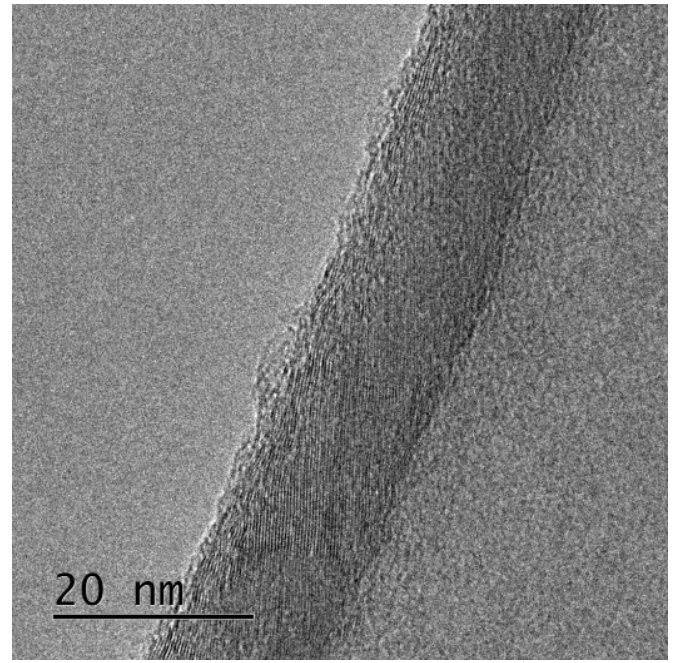

(a)

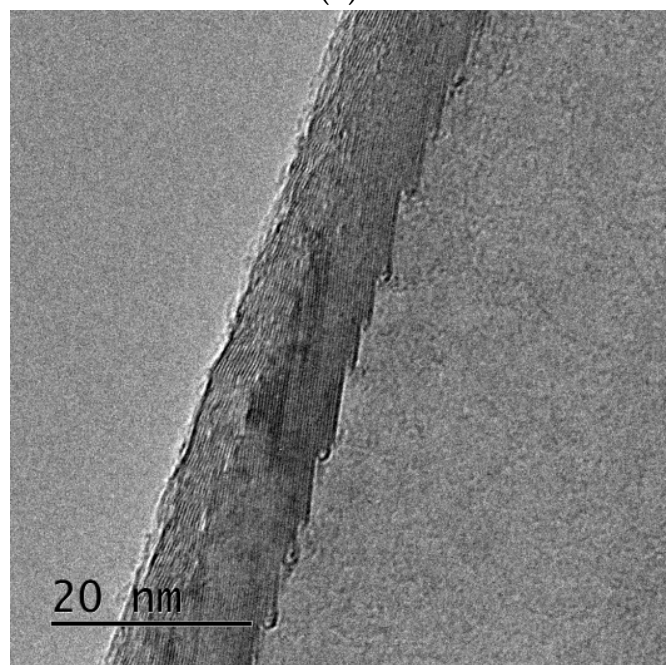

(c)

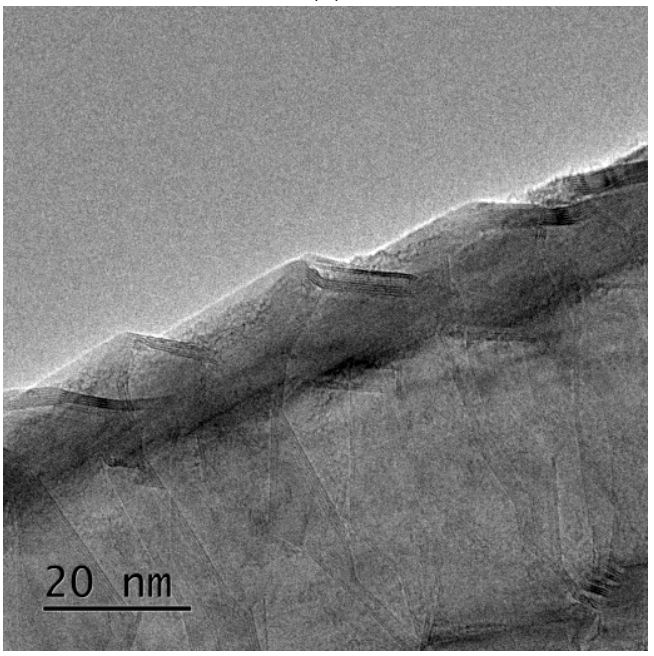

(e)

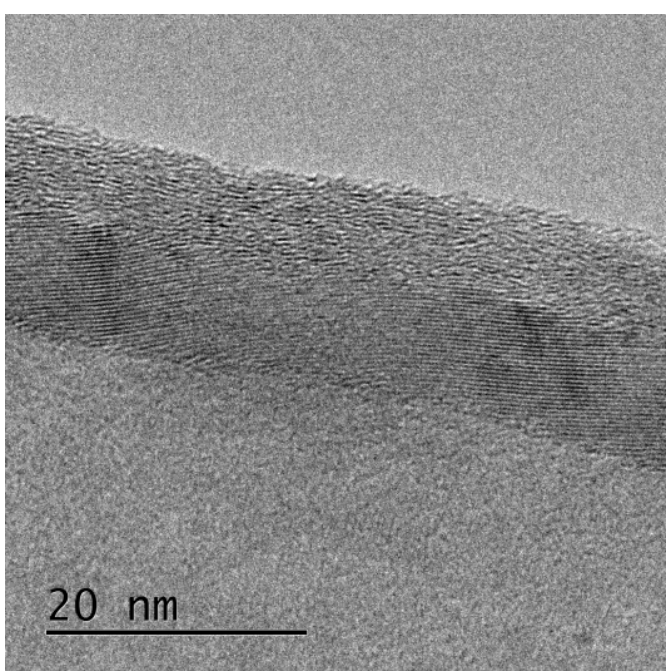

(b)

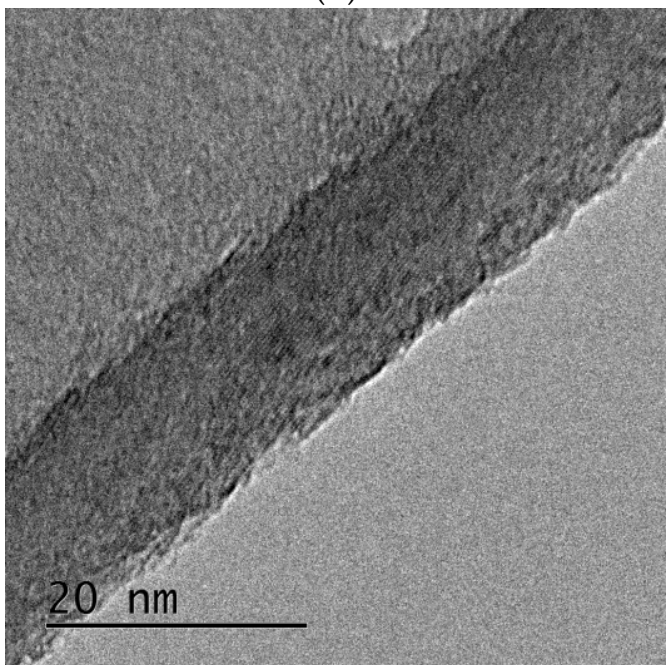

(d)

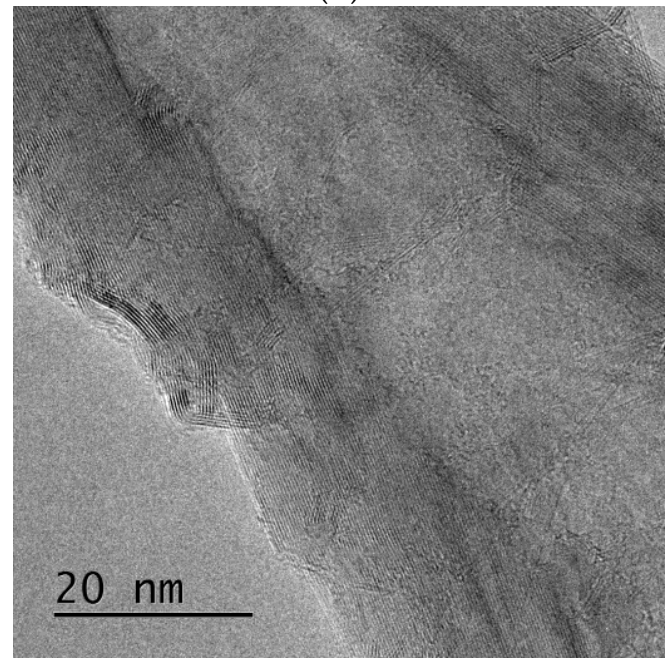

(f)

Figure 2. Microstructure characterization of carbon nanofibers (a) PS-CNFs; (b) P-PS-CNFs; (c) LHT-CNFs; (d) P-LHT-CNFs; (e) HHT-CNFs; and (f) P-HHT-CNFs. 
The elemental composition and the local distribution of $\mathrm{O}$ - and $\mathrm{P}$ - atoms were determined by energy-dispersive X-ray spectroscopy (EDS) in FEG-SEM. Figure 3 shows examples for the analysis of HHT CNFs. The EDS mappings confirmed that both $\mathrm{O}$ - and $\mathrm{P}$ - functionalities were successfully introduced in the carbon nanofibers. In all cases $\mathrm{P}$ groups were homogeneously dispersed on the surface of carbon nanofibers.

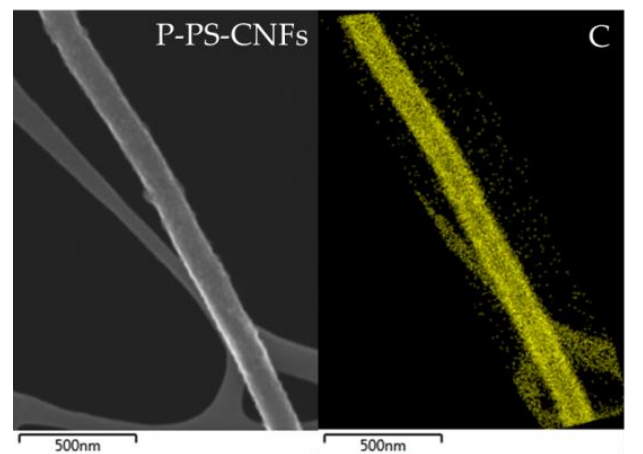

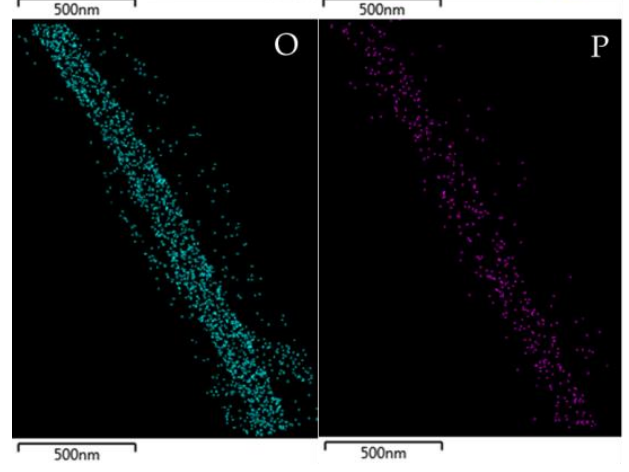

(a)
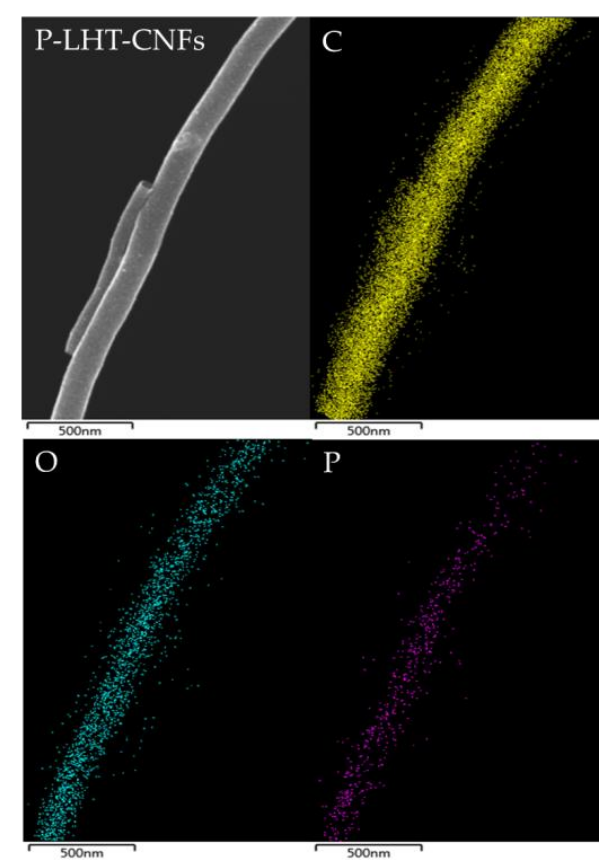

(b)

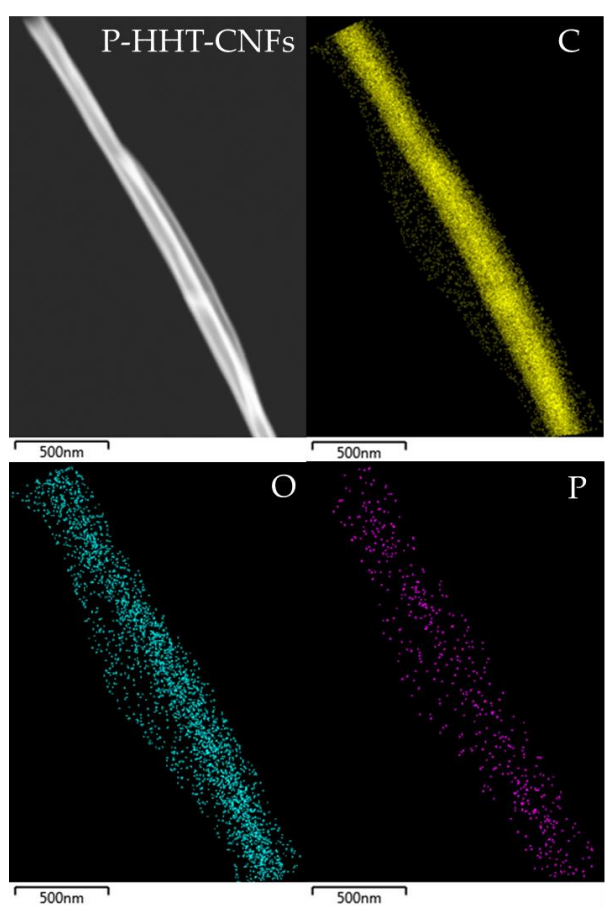

(c)

Figure 3. FEG-SEM and EDX mapping images of functionalized (a) P-PS-CNFs, (b) P-LHT-CNFs, and (c) P-HHT-CNFs. 
A quantification of $\mathrm{O}, \mathrm{P}$, and $\mathrm{C}$ species at carbon material surfaces was performed by $\mathrm{X}$-ray photoelectron spectroscopy (Tables 3 and 4).

Table 3. Surface atomic composition from X-ray photoelectron spectroscopy (XPS) analysis.

\begin{tabular}{cc}
\hline Sample & Atomic Ratio \% C:O:P \\
\hline P-PS-CNFs & $87.12: 12.65: 0.23$ \\
P-PS-CNFs-used & $85.08: 14.85: 0.07$ \\
P-LHT-CNFs & $96.06: 3.70: 0.24$ \\
P-LHT-CNFs-used & $92.74: 7.25: 0.01$ \\
P-HHT-CNFs & $90.89: 7.92: 1.19$ \\
P-HHT-CNFs-used & $81.84: 18.11: 0.05$ \\
calc P-HHT-CNFs & $91.65: 7.37: 0.98$ \\
calc P-HHT-CNFs-used & $80.32: 19.56: 0.12$ \\
\hline
\end{tabular}

Table 4. XPS analysis of P-functionalized samples before and after their use.

\begin{tabular}{|c|c|c|c|c|c|c|c|c|c|}
\hline \multirow[b]{2}{*}{ Sample } & & \multicolumn{3}{|c|}{ O1S } & \multicolumn{2}{|l|}{ P1S } & \multicolumn{2}{|c|}{ C1s } & \multirow[b]{2}{*}{$\mathrm{C}=\mathrm{C}$} \\
\hline & & $\begin{array}{l}\mathrm{C}=\mathrm{O}, \\
\mathrm{P}=\mathrm{O}, \\
\mathrm{P}-\mathrm{O}\end{array}$ & $\begin{array}{c}\mathrm{C}-\mathrm{O} \text {, } \\
\mathrm{C}-\mathrm{O}-\mathrm{C}, \\
\mathrm{P}-\mathrm{O}-\mathrm{C}\end{array}$ & $\mathrm{H}_{2} \mathrm{O}$ & $\begin{array}{c}\mathrm{C}-\mathrm{O}-\mathrm{PO}_{3} \\
\mathrm{C}-\mathrm{P}\end{array}$ & sp2 & $\begin{array}{l}\text { sp3 } \\
\text { C-P }\end{array}$ & $\mathrm{C}=\mathrm{O}$ & \\
\hline P-PS-CNFs & $\begin{array}{c}\mathrm{BE} \\
\text { Atom \% }\end{array}$ & $\begin{array}{l}531.6 \\
(50.1)\end{array}$ & $\begin{array}{l}533.3 \\
(44.5)\end{array}$ & $\begin{array}{l}535.6 \\
(5.4)\end{array}$ & $\begin{array}{l}133.7 \\
(100)\end{array}$ & $\begin{array}{l}284.5 \\
(77.4)\end{array}$ & $\begin{array}{l}285.0 \\
(14.4)\end{array}$ & $\begin{array}{l}288.5 \\
(5.7)\end{array}$ & $\begin{array}{l}291.1 \\
(2.5)\end{array}$ \\
\hline P-PS-CNFs-used & $\begin{array}{c}\mathrm{BE} \\
\text { Atom \% }\end{array}$ & $\begin{array}{l}531.6 \\
(49.1)\end{array}$ & $\begin{array}{l}533.3 \\
(44.2)\end{array}$ & $\begin{array}{l}535.9 \\
(6.7)\end{array}$ & $\begin{array}{l}133.7 \\
(100)\end{array}$ & $\begin{array}{l}284.5 \\
(73.9)\end{array}$ & $\begin{array}{l}285.1 \\
(15.9)\end{array}$ & $\begin{array}{c}288.4 \\
(7.1)\end{array}$ & $\begin{array}{l}291.1 \\
(3.1)\end{array}$ \\
\hline P-LHT-CNFs & $\begin{array}{c}\mathrm{BE} \\
\text { Atom \% }\end{array}$ & $\begin{array}{l}531.3 \\
(35.6)\end{array}$ & $\begin{array}{l}532.8 \\
(58.2)\end{array}$ & $\begin{array}{l}536.2 \\
(6.2)\end{array}$ & $\begin{array}{l}133.8 \\
(100)\end{array}$ & $\begin{array}{l}284.4 \\
(86.8)\end{array}$ & $\begin{array}{l}284.9 \\
(7.4)\end{array}$ & $\begin{array}{c}287.9 \\
(2.6)\end{array}$ & $\begin{array}{l}290.1 \\
(3.2)\end{array}$ \\
\hline P-LHT-CNFs-used & $\begin{array}{c}\text { BE } \\
\text { Atom \% }\end{array}$ & $\begin{array}{l}531.6 \\
(20.0)\end{array}$ & $\begin{array}{l}533.2 \\
(76.2)\end{array}$ & $\begin{array}{l}535.6 \\
(3.8)\end{array}$ & $\begin{array}{l}133.7 \\
(100)\end{array}$ & $\begin{array}{l}284.5 \\
(85.5)\end{array}$ & $\begin{array}{l}285.0 \\
(7.3)\end{array}$ & $\begin{array}{c}287.6 \\
(4.8)\end{array}$ & $\begin{array}{l}290.5 \\
(2.4)\end{array}$ \\
\hline P-HHT-CNFs & $\begin{array}{c}\mathrm{BE} \\
\text { Atom \% }\end{array}$ & $\begin{array}{l}532.5 \\
(31.9)\end{array}$ & $\begin{array}{l}533.8 \\
(64.7)\end{array}$ & $\begin{array}{l}536.1 \\
(3.3)\end{array}$ & $\begin{array}{l}133.4 \\
(100)\end{array}$ & $\begin{array}{l}284.5 \\
(94.5)\end{array}$ & $\begin{array}{c}285.1 \\
(2.4)\end{array}$ & $\begin{array}{l}287.7 \\
(1.1)\end{array}$ & $\begin{array}{l}291.0 \\
(2.0)\end{array}$ \\
\hline P-HHT-CNFs-used & $\begin{array}{c}\mathrm{BE} \\
\text { Atom \% }\end{array}$ & $\begin{array}{l}532.5 \\
(70.3)\end{array}$ & $\begin{array}{l}533.8 \\
(26.8)\end{array}$ & $\begin{array}{l}536.0 \\
(2.9)\end{array}$ & $\begin{array}{l}133.4 \\
(100)\end{array}$ & $\begin{array}{l}284.5 \\
(70.2)\end{array}$ & $\begin{array}{l}285.2 \\
(19.0)\end{array}$ & $\begin{array}{l}287.5 \\
(9.5)\end{array}$ & $\begin{array}{r}290.9 \\
(1.3)\end{array}$ \\
\hline calc P-HHT-CNFs & $\begin{array}{c}\mathrm{BE} \\
\text { Atom \% }\end{array}$ & $\begin{array}{l}531.4 \\
(61.3)\end{array}$ & $\begin{array}{l}533.0 \\
(33.2)\end{array}$ & $\begin{array}{l}536.0 \\
(5.5)\end{array}$ & $\begin{array}{l}134.2 \\
(100)\end{array}$ & $\begin{array}{l}284.5 \\
(93.6)\end{array}$ & $\begin{array}{c}285.0 \\
(2.9)\end{array}$ & $\begin{array}{c}287.1 \\
(1.1)\end{array}$ & $\begin{array}{l}290.9 \\
(2.4)\end{array}$ \\
\hline $\begin{array}{c}\text { calc } \\
\text { P-HHT-CNFs-used }\end{array}$ & $\begin{array}{c}\mathrm{BE} \\
\text { Atom \% }\end{array}$ & $\begin{array}{l}531.9 \\
(23.4)\end{array}$ & $\begin{array}{l}533.2 \\
(73.0)\end{array}$ & $\begin{array}{c}536.2 \\
(3.6)\end{array}$ & $\begin{array}{l}134.2 \\
(100)\end{array}$ & $\begin{array}{l}284.5 \\
(64.6)\end{array}$ & $\begin{array}{l}285.2 \\
(22.9)\end{array}$ & $\begin{array}{c}287.3 \\
(9.0)\end{array}$ & $\begin{array}{r}290.9 \\
(3.5)\end{array}$ \\
\hline
\end{tabular}

XPS analysis of the different supports confirmed that P-functionalities were introduced on the CNF surfaces A similar amount of $\mathrm{P}$ was found on the surface of P-PS-CNFs and P-LHT-CNFs (0.23 and $0.24 \%$, respectively (Table 3$)$, whereas a higher amount of $\mathrm{P}$ species were observed on P-HHT-CNFs (1.19\%). The calcination step decreased the amount of P from $1.19 \%$ to $0.98 \%$. Table 3, and Figures 4-6, summarize the chemical species observed on the surface, their concentration, and the overall elemental composition. Peak assignments were made according to phosphorylated carbons [45] and to oxidized carbon nanotubes [46] reported previously. In the C1s region we can identified four different components in the BE range of 283-295 eV. The signal at $284.5 \mathrm{eV}$ can be associated to the graphitic carbon $\left(\mathrm{C} \mathrm{sp}^{2}\right)$, the signal at 285 to $\mathrm{C} \mathrm{sp}^{3}$, the one at $288.5 \mathrm{eV}$ with the $\mathrm{C}=\mathrm{O}$ (i.e., alcohol, phenol,) and the peak at 291.1 with aromatic ring. Analyzing the O1s signal, three main oxygen groups were identified. $\mathrm{BE}$ of $531.6-532.5 \mathrm{eV}$ can be assigned to a carbon-oxygen double bond and to $\mathrm{P}=\mathrm{O}$ and $\mathrm{P}-\mathrm{O}$ species, the signal around $533 \mathrm{eV}$ to $\mathrm{C}-\mathrm{O}, \mathrm{C}-\mathrm{O}-\mathrm{C}, \mathrm{P}-\mathrm{O}-\mathrm{C}$, and the signal at $538.5 \mathrm{eV}$ can be assigned to adsorbed water and/or oxygen [47].

The comparison of TEM images pristine and functionalized materials revealed slight differences in the graphitization degree, which needed to be investigated deeper in the detail. The graphitization degree is a key parameter for describing the structural order of carbon materials. Eventual changes in 
the graphitization degree provide clear evidence that structural modifications and/or an increase in the number of defects occurred. We used Raman spectroscopy to investigate the graphitization degree of carbon materials. Two characteristic bands at $1597-1599 \mathrm{~cm}^{-1}$ (G band) and $1288-1315 \mathrm{~cm}^{-1}$ (D band), respectively, can be usually observed in the Raman spectra of carbonaceous materials. The $G$ band is generated by the allowed $C=C$ stretching vibrations of $E_{2 g}$ in the hexagonal graphite lattice and, therefore, it is related to structurally-ordered graphite domains [48]. On the contrary, the D band corresponds to the $A_{1 \mathrm{~g}}$ mode that is forbidden according to the selection rules in graphite, but it is activated in the presence of structural defects or in plane substitutional heteroatoms. The appearance of an additional $\mathrm{D}$ band was then associated with the turbostratic and/or disordered carbonaceous structures [48]. Consequently, the ratio of the integral intensities of $\mathrm{D}$ and $\mathrm{G}$ bands, respectively, $I_{\mathrm{D}} / I_{\mathrm{G}}$ is an index of the defectiveness of the graphite layers.

In all the Raman spectra of functionalized materials $G$ and D bands have been observed. Comparing the graphitization degree of pristine and functionalized materials, no clear trends can be detected. Indeed, for PS-CNFs the functionalization seems to decrease the defectiveness of the materials (Table 5). This might appear as an unexpected result, since the introduction of functional chemical groups should entail the formation of $\mathrm{sp}^{3}$ carbon and defects, thus inducing an increase of the $\mathrm{D}$ band and, consequently, of the $I_{\mathrm{D}} / I_{\mathrm{G}}$ ratio. Actually, as reported in the literature, acidic oxidation treatment produces the opening of the closed loop ends on the surface of CNFs, thus favoring the overall alignment of hexagonal planes and resulting in an enhanced graphitization [49-51]. Moreover, the functionalization can remove the amorphous carbon present on the external surface of PS-CNFs. This phenomenon could compensate for the increased defectiveness deriving from the functionalization. On the contrary, as expected the functionalization increases the defectiveness of the LHT CNFs, whereas no significant modifications were observed for HHT CNFs.

Table 5. Graphitization degree from Raman spectra.

\begin{tabular}{cccc}
\hline \multirow{2}{*}{ Sample Name } & \multicolumn{3}{c}{ Graphitization Degree $\left(\mathbf{I}_{\mathbf{D}} / \mathbf{I}_{\mathrm{G}}\right)^{\mathbf{1}}$} \\
\cline { 2 - 4 } & Pristine & P-Functionalised & After Reaction \\
\hline PS-CNFs & 0.75 & 0.58 & 1.16 \\
LHT CNFs & 0.71 & 1.01 & 1.11 \\
HHT CNFs & 0.11 & 0.09 & 0.34 \\
Calcined Funct-HHT CNFs & 0.11 & 0.36 & 0.38 \\
\hline 1 The peak fitting analysis was performed based on Gaussian functions.
\end{tabular}

Clearer and rationalizable differences can be disclosed before and after the use of functionalized materials as catalysts in the fructose dehydration reaction. In all samples after the catalytic tests a significant increase in the defectiveness $\left(I_{\mathrm{D}} / I_{\mathrm{G}}\right.$ ratio) was observed. This evidence could be ascribed to the presence of reaction by-products adsorbing on the carbon nanofiber surface, thus providing a possible explanation to the deactivation observed in the catalytic tests. 

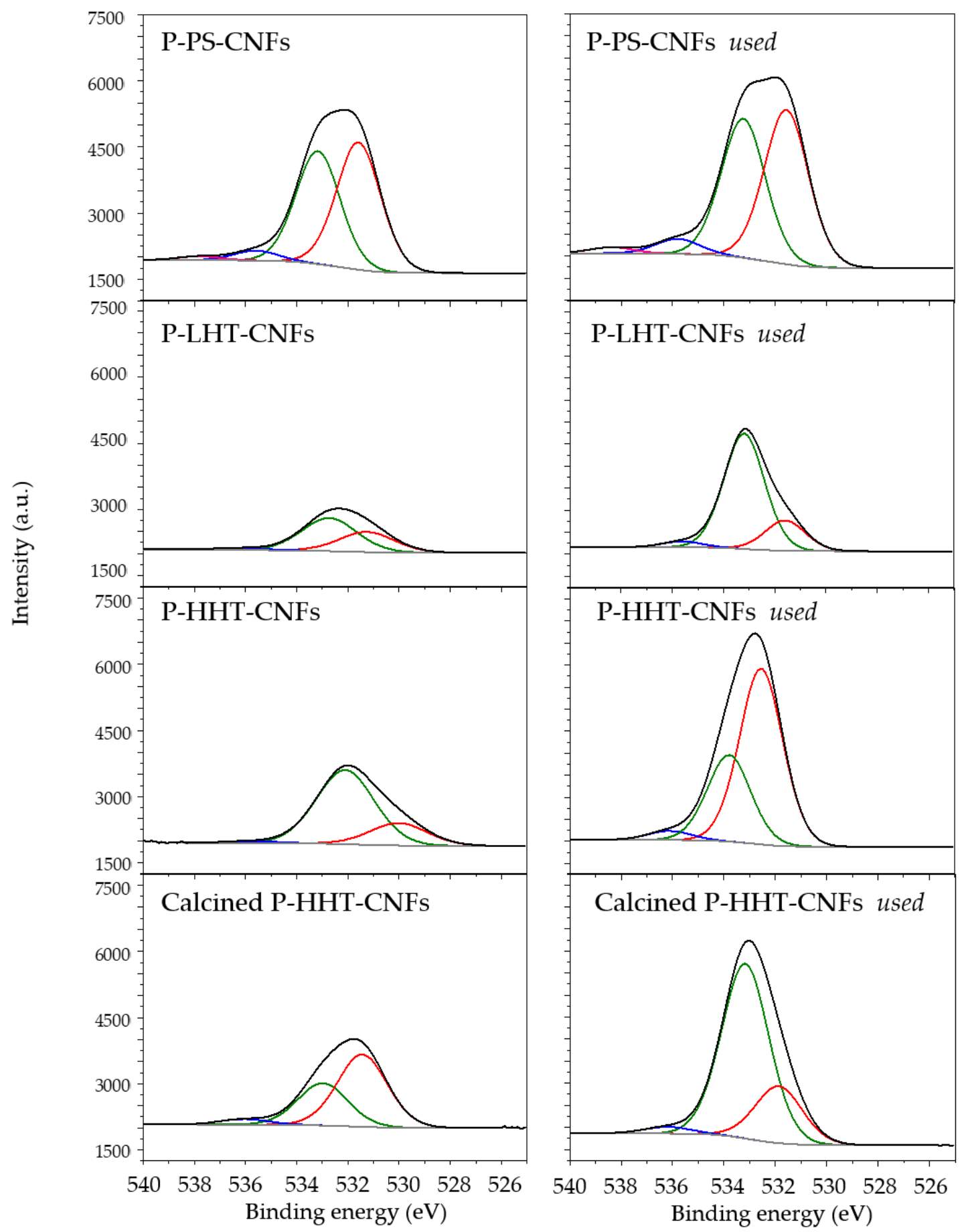

Figure 4. O1s analysis of P-functionalized samples before (on the left) and after (on the right) their use. 


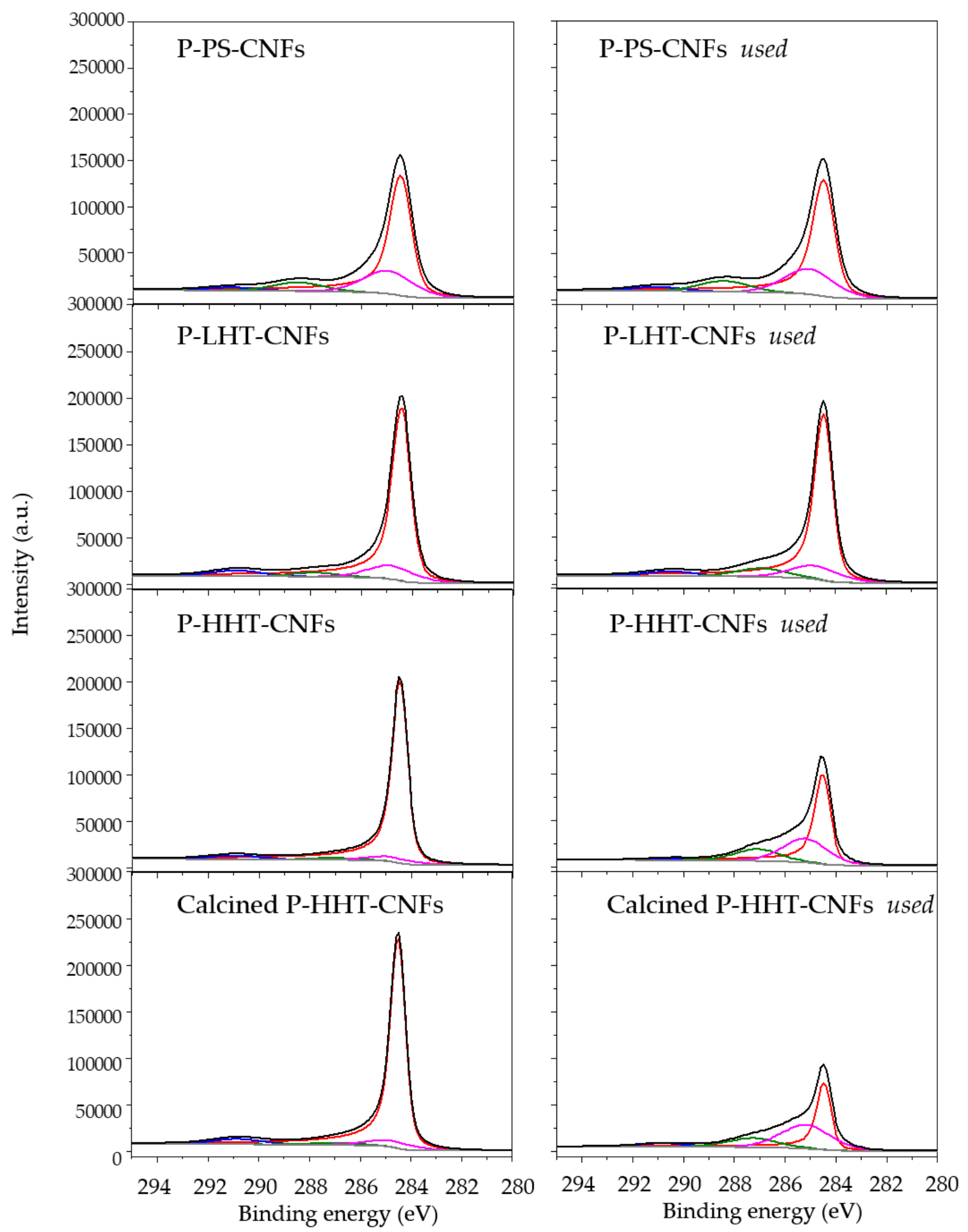

Figure 5. C1s analysis of P-functionalized samples before (on the left) and after (on the right) their use. 

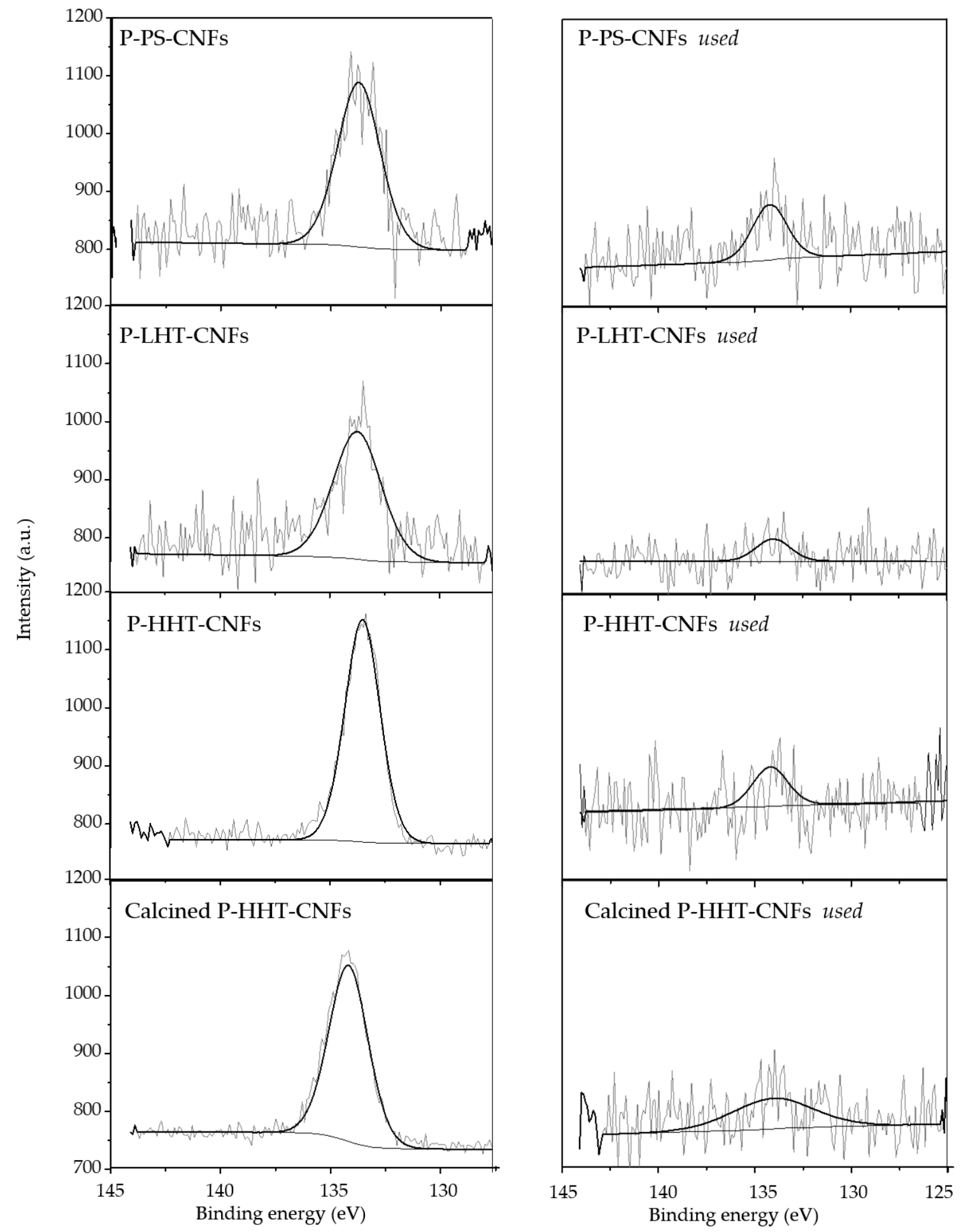

Figure 6. P2p analysis of P-functionalized samples before (on the left) and after (on the right) their use.

\section{Discussion}

The role of the graphitization degree in controlling and directing the introduction of $\mathrm{P}$ functionalities on the CNF surface has been investigated specifically for three different samples, PS-CNFs, LHT-CNFs, and HHT-CNFs. In all these cases, the use of a $\mathrm{H}_{3} \mathrm{PO}_{4}-\mathrm{HNO}_{3}$ mixture in relatively mild conditions $\left(150{ }^{\circ} \mathrm{C}\right)$ resulted in being an effective strategy to functionalize the $\mathrm{CNF}$ surfaces without strongly altering the morphology of the fibers, as revealed by electron microscopies. 
Phosphorus atoms were present at the surface of CNFs in an atomic concentration ranging between 0.2 and $1 \%$, according to the XPS analysis. Surprisingly, the highest content of phosphorus $(1.19 \%)$ was observed for HHT CNFs, characterized by a high graphitization degree. This result might be explained by considering the high amount of surface free edges in graphitic CNFs, which could undergo easy functionalization. Indeed, as reported by Lim et al. [50], acidic oxidation results in the opening of the numerous closed loop end in graphitic CNFs and in the subsequent formation of free edges, which are more prone to surface functionalization. The analysis of O1s and C1s XPS signals revealed that, as expected, in all cases the insertion of $\mathrm{P}$ functionalities occurred preferentially by formation of $\mathrm{C}-\mathrm{O}-\mathrm{P}$ bonds. Different alterations in the graphitization degree, as calculated from the Raman spectra, were observed after the functionalization treatment for the different CNFs. This evidence could be essentially ascribed to three effects: the relatively low functionalization degree, the removal of amorphous carbon, and the graphitization induced by acidic treatment cutting off the closed-loop ends of CNFs.

The extent of the functionalization and the relative concentration of $\mathrm{P}$ functionalities on the CNF surface reflected on the catalytic performances in the fructose dehydration reaction. The selective dehydration of fructose to HMF is an acid-catalyzed reaction. Brønsted acid sites and, in particular, phosphate groups are known to be active catalysts for this reaction [34-37]. Actually, correlating the final conversion after $12 \mathrm{~h}$ and the P concentration on the surface, as determined by XPS, a clear correlation between activity and amount of $P$ groups (Figure 7) appears. The dependence of the conversion on the $\mathrm{P}$ content reflected the acidity scale of the materials, as obtained by acid site titration (Table 6).

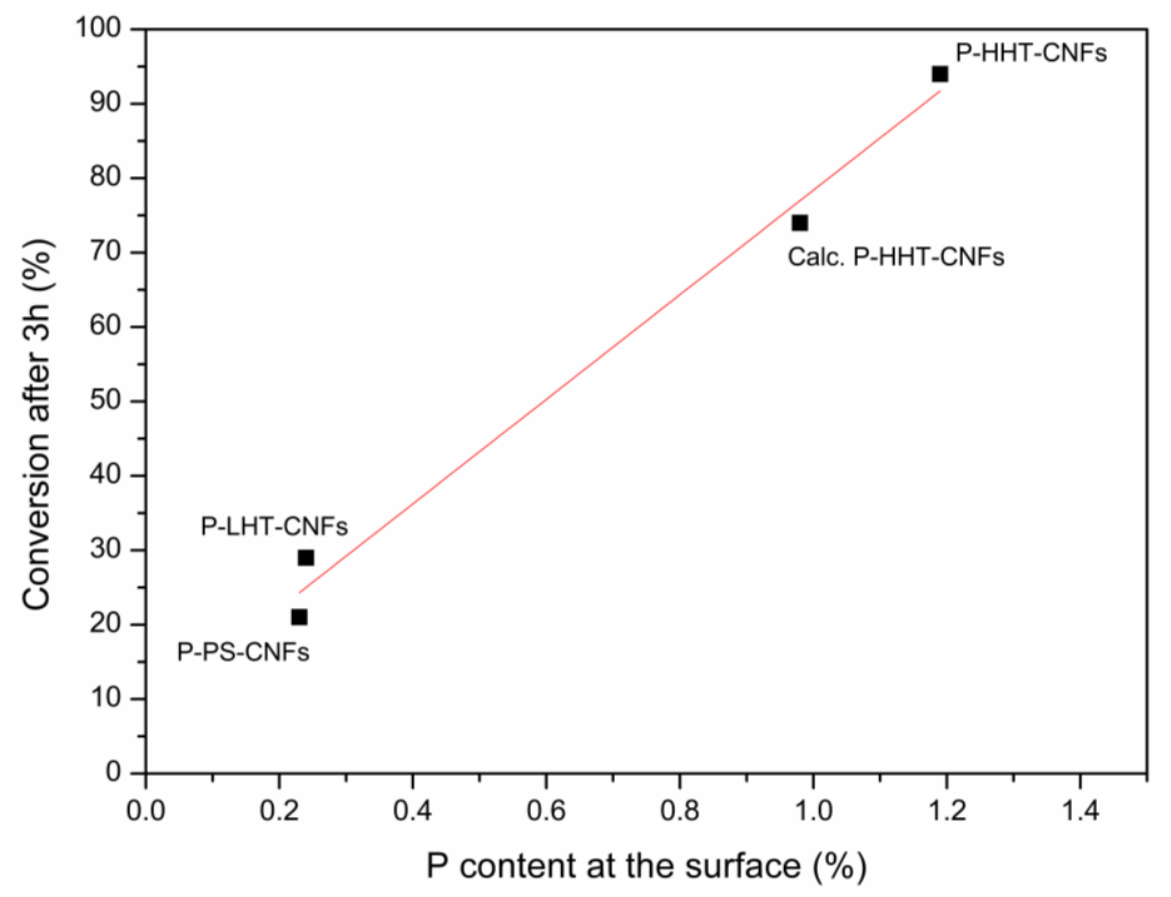

Figure 7. Correlation between catalyst activity and surface P content.

P-HHT CNFs, which possessed the highest $\mathrm{P}$ content and the highest number of acid sites, demonstrated to be the most active catalyst in fructose dehydration, reaching full conversion after $12 \mathrm{~h}$. On the contrary, P-PS CNFs and P-LHT CNFs suffered from fast deactivation after $3 \mathrm{~h}$, probably due to the leaching of phosphate groups, as suggested by the XPS analysis of used catalysts, revealing a remarkable decrease in the amount of $P$ at the surface. This fact can be due to the leaching of $P$ species into the solution as evidenced by the hot filtration test, where the reaction slowly proceeded even in the absence of the solid catalysts. In any case, we cannot exclude a concomitant blocking effect due to the deposit of solid carbonaceous by-products (e.g., humins) on the surface. The last hypothesis 
seems to be supported by the increase in the surface oxygen concentration (Table 3) and the decrease of graphitization degree (Table 5) observed in used catalysts.

Table 6. Quantification of acid sites.

\begin{tabular}{cc}
\hline Sample & Acid Site $\left(\mathbf{m m o l ~ g}^{\mathbf{- 1}}\right)$ \\
\hline P-PS-CNFs & $0.116 \pm 0.093$ \\
P-LHT-CNFs & $0.343 \pm 0.032$ \\
P-HHT-CNFs & $1.257 \pm 0.009$ \\
Calc. P-HHT-CNFs & $0.797 \pm 0.015$ \\
\hline
\end{tabular}

In all cases HMF was the main product, even if the selectivity to this target molecule was always lower than 50\%. The low selectivity to HMF might be attributed again to the leaching of phosphate groups, as confirmed by the hot filtration test. According to the literature, phosphate groups eventually dissolved in the solution would act as homogenous catalysts promoting several secondary reactions and the subsequent transformation of HMF into by-products [36,40-43]. This hypothesis was supported by the results obtained by performing the reaction under the same conditions using phosphoric acid as the homogeneous catalyst (see Table 1). Despite the high activity, fructose was not selectively converted to HMF in the presence of $\mathrm{H}_{3} \mathrm{PO}_{4}$. Based on these experimental evidences, we decided to test P-HHT CNFs after calcination. According to previous works, the thermal treatment led to the transformation of $\mathrm{C}-\mathrm{O}-\mathrm{P}$ bonds into stronger and more stable $\mathrm{C}-\mathrm{P}$ bonds [44]. This assumption was confirmed in our experiments. Indeed, observing the O1s signal, calc. P-HHT-CNFs showed a lower contribution of P-O-C species at $533.2 \mathrm{eV}(33.2 \%)$ compared to the uncalcined P-HHT-CNFs sample (64.7\%). On the contrary the contribution of C-P signal at $285.2 \mathrm{eV}$ (from XPS results) increased during the calcination from 2.4 to $2.9 \%$ (Table 4). Minimizing phosphate leaching allowed to obtain active and selective catalysts in fructose dehydration. The better resistance against deactivation of calc. P-HHT CNFs stability tests were performed. Recycling experiments were carried out by filtering and using the catalyst in the next run without any further purification. The catalyst first showed a gradual loss in the activity (15\%) along the first two cycles, maintaining almost the same activity and selectivity during successive the four cycles (Figure 8).

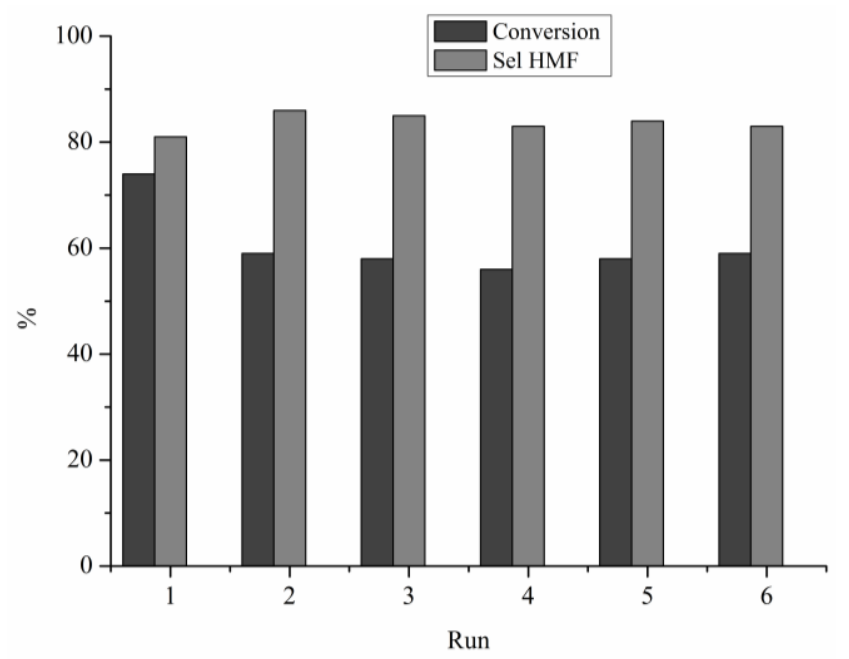

Figure 8. Stability tests on calc. P-HHT CNFs. Reaction time: $12 \mathrm{~h}$. 


\section{Materials and Methods}

\subsection{Material Functionalization}

Commercial CNFs PR24-PS from Applied Science (average diameter of $100 \pm 30 \mathrm{~nm}$ and a specific surface area of $45 \mathrm{~m}^{2} / \mathrm{g}$ ), CNFs PR24-LHT from Applied Science (average diameter of $100 \pm 30 \mathrm{~nm}$ and a specific surface area of $43 \mathrm{~m}^{2} / \mathrm{g}$ ) and CNFs PR24-HHT from Applied Science (average diameter of $100 \pm 30 \mathrm{~nm}$ and a specific surface area of $41 \mathrm{~m}^{2} / \mathrm{g}$ ) were used as pristine carbon materials. For the functionalization $2 \mathrm{~g}$ of $\mathrm{CNF}$ sample were suspended in $250 \mathrm{~mL}$ of a $\mathrm{HNO}_{3}-\mathrm{H}_{3} \mathrm{PO}_{4} 1: 1 v / v$ mixture, stirred and heated at $150{ }^{\circ} \mathrm{C}(2 \mathrm{~h})$. As-functionalized carbon samples were then filtered, thoroughly washed with distilled water until neutrality, and finally dried at $100{ }^{\circ} \mathrm{C}$ overnight.

\subsection{Catalytic Tests}

Fructose (from Sigma Aldrich, >99\%) $5 \mathrm{wt} \%$ and the catalyst (substrate/catalyst $=2 / 1 w / w$ ) were mixed in distilled water (total volume $10 \mathrm{~mL}$ ). Reactions were carried out in a $30 \mathrm{~mL}$ glass reactor equipped with a thermostat and an electronically-controlled magnetic stirrer connected to a $5000 \mathrm{~mL}$ reservoir charged with nitrogen $(300 \mathrm{kPa})$. The reactor was pressurized at $300 \mathrm{kPa}$ of nitrogen and set to $120^{\circ} \mathrm{C}$. Once this temperature was reached, the monitoring of the reaction started. The reaction was initiated by stirring. Samples were removed periodically and analyzed by high-performance liquid chromatography (HPLC) using a column (Alltech OA-10308, Fisher Scientific, Hampton, NH, USA, $300 \mathrm{~mm} 7.8 \mathrm{~mm}$ ) with UV and refractive index (RI) detection to analyze the mixture of the samples. Aqueous $\mathrm{H}_{3} \mathrm{PO}_{4}$ solution $(0.1 \mathrm{wt} \%$ ) was used as the eluent. Products were identified by comparison with the original samples.

Recycling test: each run was carried out under the same conditions (Fructose 5 wt \%; substrate/catalyst $=2 / 1 \mathrm{w} / \mathrm{w}, 120^{\circ} \mathrm{C}, 3$ bar $\mathrm{N}_{2}$ ). The catalyst was recycled in the subsequent run after filtration without any further treatment.

\subsection{Catalyst Characterization}

X-ray photoelectron spectroscopy (XPS) was performed on a Thermo Scientific K-alpha+ spectrometer (Waltham, MA, USA). Samples were analyzed using a monochromatic Al X-ray source (Waltham, MA, USA) operating at $72 \mathrm{~W}(6 \mathrm{~mA} \times 12 \mathrm{kV})$, with the signal averaged over an oval-shaped area of approximately $600 \times 400$ microns. Data were recorded at pass energies of $150 \mathrm{eV}$ for survey scans and $40 \mathrm{eV}$ for high-resolution scans with a 1 and $0.1 \mathrm{eV}$ step size, respectively. Charge neutralization of the sample was achieved using a combination of both low energy electrons and argon ions (less than $1 \mathrm{eV}$ ), which gave a C1s binding energy of $284.8 \mathrm{eV}$.

All data were analyzed using CasaXPS (v2.3.17 PR1.1, Teignmouth, UK) using Scofield sensitivity factors and an energy exponent of -0.6 .

Samples for examination by transmission electron microscopy (TEM) were prepared by dispersing the catalyst powder in high-purity ethanol using ultra-sonication. Forty microliters of the suspension was dropped on to a holey carbon film supported by a 300 mesh copper TEM grid before the solvent was evaporated. The samples for TEM were then examined using a JEOL JEM 2100 TEM model (Peabody, MA, USA) operating at $200 \mathrm{kV}$. The morphology and composition was examined by scanning emission microscopy on a Tescan MAIA 3 field emission gun scanning electron microscope (FEG-SEM, Brno, Czech Republic) fitted with secondary and backscattered electron detection. Energy-dispersive X-ray (EDX) analysis and mapping was done using Oxford Instruments $\mathrm{X}-\mathrm{Max}^{\mathrm{N}} 80$ detector (Abingdon-on-Thames, UK) and the data analyzed using Aztec software (Bangalore, India). Samples were mounted on 300 mesh copper grids coated holey carbon film and analyzed uncoated.

The acid sites on the CNF surface were determined through retro-titration. For this purpose, $0.2000 \mathrm{~g}$ of each material was mixed with $100.0 \mathrm{~mL}$ of sodium hydroxide $0.1 \mathrm{M}$ solution for $2 \mathrm{~h}$ under 
$\mathrm{N}_{2}$ and constant magnetic stirring. The solid was separated by filtration and three aliquots of $20.0 \mathrm{~mL}$ of each solution were titrated with $0.1 \mathrm{M}$ hydrochloric acid solution.

Nitrogen sorption measurements were performed using a Horiba SA-9601 instrument (Kyoto, Japan).

\section{Conclusions}

In summary, we demonstrated that highly graphitic carbon nanofibers can be easily phosphorylated by treatment with $\mathrm{HNO}_{3}-\mathrm{H}_{3} \mathrm{PO}_{4}$ mixture. This procedure results in the formation of $\mathrm{C}-\mathrm{O}-\mathrm{P}$ groups, which are active in the fructose dehydration, but not stable under the reaction conditions tending to be released with detrimental effects on the catalytic performances. High-temperature treatment represents a suitable strategy to create stronger C-P bonds, less susceptible to leaching and, consequently, to obtain more active and selective catalysts. These results represent an interesting starting point towards the design of tailored carbon-based materials for catalytic applications. To this aim, future studies will be devoted to the optimization of the functionalization procedure in order to control the density, the type, and the location of P-functionalities.

Acknowledgments: The authors acknowledge the Cardiff University for providing EM and XPS facilities, and thank David Morgan for his technical assistance. The authors are also immensely grateful to Marco Schiavoni (Università degli Studi di Milano), who provided insight and expertise that greatly assisted the research.

Author Contributions: Sebastiano Campisi and Alberto Villa designed the experiments and carried out the catalytic evaluation; Davide Motta carried out the XPS experiments and helped in the interpretation; Felipe Sanchez Trujillo and Thomas E. Davies carried out the Raman, TEM, and SEM experiments and helped in the interpretation; Sebastiano Campisi and Alberto Villa analyzed the data; and Sebastiano Campisi, Alberto Villa, Nikolaos Dimitratos were involved in the writing and editing the manuscript.

Conflicts of Interest: The authors declare no conflict of interest.

\section{References}

1. Van Santen, R.A. Modern Heterogeneous Catalysis: An Introduction, 1st ed.; Wiley-VCH: Weinheim, Germany, 2017; pp. 1-166. ISBN 978-3-527-33961-7.

2. Rodríguez-Reinoso, F. The role of carbon materials in heterogeneous catalysis. Carbon 1998, 36, $159-175$. [CrossRef]

3. Serp, P.; Figueiredo, J.L. Carbon Materials for Catalysis, 1st ed.; John Wiley \& Sons Inc.: Hoboken, NJ, USA, 2009; pp. 1-218. ISBN 9780470178850.

4. Liu, X.; Dai, L. Carbon-based metal-free catalysts. Nat. Rev. Mater. 2016, 1, 16064. [CrossRef]

5. Lam, E.; Luong, J.H.T. Carbon materials as catalyst supports and catalysts in the transformation of biomass to fuels and chemicals. ACS Catal. 2014, 4, 3393-3410. [CrossRef]

6. Su, D.S.; Zhang, J.; Frank, B.; Thomas, A.; Wang, X.; Paraknowitsch, J.; Schlögl, R. Metal-Free heterogeneous catalysis for sustainable chemistry. ChemSusChem 2010, 3, 169-180. [CrossRef] [PubMed]

7. Pierson, H.O. Handbook of Carbon, Graphite, Diamonds and Fullerenes: Processing, Properties and Applications, 1st ed.; Noyes Publications: New York, NY, USA, 1993; pp. 70-86. ISBN 0815513399.

8. Bitter, J.H. Nanostructured carbons in catalysis a Janus material—Industrial applicability and fundamental insights. J. Mater. Chem. 2010, 20, 7312-7321. [CrossRef]

9. Serp, P.; Machado, B. Nanostructured Carbon Materials for Catalysis, 1st ed.; Royal Society of Chemistry: Cambridge, UK, 2015; pp. 1-267.

10. Yu, D.; Nagelli, E.; Du, F.; Dai, L. Metal-Free carbon nanomaterials become more active than metal catalysts and last longer. J. Phys. Chem. Lett. 2010, 1, 2165-2173. [CrossRef]

11. Pan, X.; Bao, X. The effects of confinement inside carbon nanotubes on catalysis. Acc. Chem. Res. 2011, 44, 553-562. [CrossRef] [PubMed]

12. Chen, W.; Fan, Z.; Pan, X.; Bao, X. Effect of confinement in carbon nanotubes on the activity of Fischer-Tropsch iron catalyst. J. Am. Chem. Soc. 2008, 130, 9414-9419. [CrossRef] [PubMed]

13. Villa, A.; Wang, D.; Chan-Thaw, C.E.; Campisi, S.; Veith, G.M.; Prati, L. The confinement effect on the activity of Au NPs in polyol oxidation. Catal. Sci. Technol. 2016, 6, 598-601. [CrossRef] 
14. Guo, S.; Pan, X.; Gao, H.; Yang, Z.; Zhao, J.; Bao, X. Probing the electronic effect of carbon nanotubes in catalysis: $\mathrm{NH}_{3}$ synthesis with Ru nanoparticles. Chem. Eur. J. 2010, 16, 5379-5384. [CrossRef] [PubMed]

15. Toebes, M.L.; Zhang, Y.; Hájek, J.; Nijhuis, T.A.; Bitter, J.H.; Van Dillen, A.J.; Murzin, D.Y.; de Jong, K.P. Support effects in hydrogenation of cinnamaldehyde over carbon nanofiber-supported platinum catalysts: Characterization and catalysis. J. Catal. 2004, 226, 215-225. [CrossRef]

16. Zhu, J.; Holmen, A.; Chen, D. Carbon nanomaterials in catalysis: Proton affinity, chemical and electronic properties, and their catalytic consequences. Chem CatChem 2013, 5, 378-401. [CrossRef]

17. Zhang, J.; Su, D.S.; Blume, R.; Schlögl, R.; Wang, R.; Yang, X.; Gajović, A. Surface Chemistry and Catalytic Reactivity of a Nanodiamond in the Steam-Free Dehydrogenation of Ethylbenzene. Angew. Chem. Int. Ed. 2010, 49, 8640-8644. [CrossRef] [PubMed]

18. Sun, X.; Li, B.; Su, D. The Unexpected Reactivity of the Carbon Sites on the Nanostructured Carbon Catalysts towards the C-H Bond Activation from the Analysis of the Aromaticity. Chem. Asian J. 2016, 11, 1668-1671. [CrossRef] [PubMed]

19. Axet, M.R.; Dechy-Cabaret, O.; Durand, J.; Gouygou, M.; Serp, P. Coordination chemistry on carbon surfaces. Coord. Chem. Rev. 2016, 308, 236-345. [CrossRef]

20. Gao, J.; Ji, Y.; Li, Y.; Zhong, J.; Sun, X. The morphological effect on electronic structure and electrical transport properties of one-dimensional carbon nanostructures. RSC Adv. 2017, 7, 21079-21084. [CrossRef]

21. Li, J.; Vergne, M.J.; Mowles, E.D.; Zhong, W.H.; Hercules, D.M.; Lukehart, C.M. Surface functionalization and characterization of graphitic carbon nanofibers (GCNFs). Carbon 2005, 43, 2883-2893. [CrossRef]

22. Balasubramanian, K.; Burghard, M. Chemically functionalized carbon nanotubes. Small 2005, 1, $180-192$. [CrossRef] [PubMed]

23. Lee, W.J.; Maiti, U.N.; Lee, J.M.; Lim, J.; Han, T.H.; Kim, S.O. Nitrogen-doped carbon nanotubes and graphene composite structures for energy and catalytic applications. Chem. Commun. 2014, 50, 6818-6830. [CrossRef] [PubMed]

24. Feng, L.; Yang, L.; Huang, Z.; Luo, J.; Li, M.; Wang, D.; Chen, Y. Enhancing Electrocatalytic Oxygen Reduction on Nitrogen-Doped Graphene by Active Sites Implantation. Sci. Rep. 2013, 3, 3306. [CrossRef] [PubMed]

25. Fraga, M.A.; Jordao, E.; Mendes, M.J.; Freitas, M.M.A.; Faria, J.L.; Figueiredo, J.L. Properties of carbon-supported platinum catalysts: Role of carbon surface sites. J. Catal. 2002, 209, 355-364. [CrossRef]

26. Hara, M.; Yoshida, T.; Takagaki, A.; Takata, T.; Kondo, J.N.; Hayashi, S.; Domen, K. A carbon material as a strong protonic acid. Angew. Chem. Int. Ed. 2004, 43, 2955-2958. [CrossRef] [PubMed]

27. Villa, A.; Schiavoni, M.; Prati, L. Material science for the support design: A powerful challenge for catalysis. Catal. Sci. Technol. 2012, 2, 673-682. [CrossRef]

28. Arrigo, R.; Hävecker, M.; Wrabetz, S.; Blume, R.; Lerch, M.; McGregor, J.; Parrott, E.P.J.; Zeitler, J.A.; Gladden, L.F.; Knop-Gericke, A.; et al. Tuning the acid/base properties of nanocarbons by functionalization via amination. J. Am. Chem. Soc. 2010, 132, 9616-9630. [CrossRef] [PubMed]

29. Campisi, S.; Marzorati, S.; Spontoni, P.; Chan-Thaw, C.E.; Longhi, M.; Villa, A.; Prati, L. Tailored N-Containing Carbons as Catalyst Supports in Alcohol Oxidation. Materials 2016, 9, 114. [CrossRef] [PubMed]

30. Zhang, J.; Dai, L. Heteroatom-doped graphitic carbon catalysts for efficient electrocatalysis of oxygen reduction reaction. ACS Catal. 2015, 5, 7244-7253. [CrossRef]

31. Villa, A.; Schiavoni, M.; Chan-Thaw, C.E.; Fulvio, P.F.; Mayes, R.T.; Dai, S.; More, K.L.; Veith, G.M.; Prati, L. Acid-functionalized mesoporous carbon: An efficient support for ruthenium-catalyzed $\gamma$-valerolactone production. ChemSusChem 2015, 8, 2520-2528. [CrossRef] [PubMed]

32. Prati, L.; Chan-Thaw, C.E.; Campisi, S.; Villa, A. N-Modified Carbon-Based Materials: Nanoscience for Catalysis. Chem. Rec. 2016, 16, 2187-2197. [CrossRef] [PubMed]

33. Thakur, V.K.; Thakur, M.K. Chemical Functionalization of Carbon Nanomaterials: Chemistry and Applications; CRC Press: Boca Raton, FL, USA, 2015; p. 237. ISBN 1482253968.

34. Carniti, P.; Gervasini, A.; Biella, S.; Auroux, A. Niobic acid and niobium phosphate as highly acidic viable catalysts in aqueous medium: Fructose dehydration reaction. Catal. Today 2006, 118, 373-378. [CrossRef]

35. Zhang, Y.; Wang, J.J.; Ren, J.W.; Liu, X.H.; Li, X.C.; Xia, Y.J.; Lu, G.Z.; Wang, Y.Q. Mesoporous niobium phosphate: An excellent solid acid for the dehydration of fructose to 5-hydroxymethylfurfural in water. Catal. Sci. Technol. 2012, 2, 2485-2491. [CrossRef]

36. Carlini, C.; Patrono, P.; Galletti, A.M.R.; Sbrana, G. Heterogeneous catalysts based on vanadyl phosphate for fructose dehydration to 5-hydroxymethyl-2-furaldehyde. Appl. Catal. A 2004, 275, 111-118. [CrossRef] 
37. Villa, A.; Schiavoni, M.; Fulvio, P.F.; Mahurin, S.M.; Dai, S.; Mayes, R.T.; Veith, G.M.; Prati, L. Phosphorylated mesoporous carbon as effective catalyst for the selective fructose dehydration to HMF. J. Energy Chem. 2013, 22, 305-311. [CrossRef]

38. Aronne, A.; Di Serio, M.; Vitiello, R.; Clayden, N.J.; Minieri, L.; Imparato, C.; Piccolo, A.; Pernice, P.; Carniti, P.; Gervasini, A. An environmentally friendly Nb-P-Si solid catalyst for acid demanding reactions. J. Phys. Chem. C 2017, 121, 17378-17389. [CrossRef]

39. Tessonnier, J.-P.; Rosenthal, D.; Hansen, T.W.; Hess, C.; Schuster, M.E.; Blume, R.; Girgsdies, F.; Pfaender, N.; Timpe, O.; Su, D.S.; et al. Analysis of the structure and chemical properties of some commercial carbon nanostructures. Carbon 2009, 47, 1779-1798. [CrossRef]

40. Carniti, P.; Gervasini, A.; Marzo, M. Absence of expected side-reactions in the dehydration reaction of fructose to HMF in water over niobic acid catalyst. Catal. Commun. 2011, 12, 1122-1126. [CrossRef]

41. Moreau, C.; Durand, R.; Razigade, S.; Duhamet, J.; Faugeras, P.; Rivalier, P.; Ros, P.; Avignon, G. Dehydration of fructose to 5-hydroxymethylfurfural over H-mordenites. Appl. Catal. A Gen. 1996, 145, 211-224. [CrossRef]

42. Van Dam, H.E.; Kieboom, A.P.G.; van Bekkum, H. The Conversion of Fructose and Glucose in Acidic Media: Formation of Hydroxymethylfurfural. Starch Stärke 1986, 38, 95-101. [CrossRef]

43. Zhao, Q.; Wang, L.; Zhao, S.; Wang, X.; Wang, S. High selective production of 5-hydroymethylfurfural from fructose by a solid heteropolyacid catalyst. Fuel 2011, 90, 2289-2293. [CrossRef]

44. Wang, L.; Dong, X.; Jiang, H.; Li, G.; Zhang, M. Phosphorylated ordered mesoporous carbon as a novel solid acid catalyst for the esterification of oleic acid. Catal. Commun. 2014, 56, 164-167. [CrossRef]

45. Bedia, J.; Rosas, J.M.; Márquez, J.; Rodríguez-Mirasol, J.; Cordero, T. Preparation and characterization of carbon based acid catalysts for the dehydration of 2-propanol. Carbon 2009, 47, 286-294. [CrossRef]

46. Kundu, S.; Wang, Y.; Xia, W.; Muhler, M. Thermal Stability and Reducibility of Oxygen-Containing Functional Groups on Multiwalled Carbon Nanotube Surfaces: A Quantitative High-Resolution XPS and TPD/TPR Study. J. Phys. Chem. C 2008, 112, 16869-16878. [CrossRef]

47. Walczyk, M.; Świakkatkowski, A.; Pakuła, M.; Biniak, S. Electrochemical studies of the interaction between a modified activated carbon surface and heavy metal ions. J. Appl. Electrochem. 2005, 35, 123-130. [CrossRef]

48. Tuinstra, F.; Koenig, J.L. Raman Spectrum of Graphite. J. Chem. Phys. 1970, 53, 1126-1130. [CrossRef]

49. Lim, S.; Yoon, S.; Mochida, I. Surface Modification of Carbon Nanofiber with High Degree of Graphitization. J. Phys. Chem. 2004, 1533-1536. [CrossRef]

50. Szekeres, G.P.; Nemeth, K.; Kinka, A.; Magyar, M.; Reti, B.; Varga, E.; Szegletes, Z.; Erdohelyi, A.; Nagy, L.; Hernadi, K. Segmental nitrogen doping and carboxyl functionalization of multi-walled carbon nanotubes. Phys. Status Solidi Basic Res. 2015, 252, 2472-2478. [CrossRef]

51. Tikhomirov, A.S.; Sorokina, N.E.; Avdeev, V.V. Surface modification of carbon fibers with nitric acid solutions. Inorg. Mater. 2011, 47, 684-688. [CrossRef] 